\title{
Seepage Finite Element Analysis of Induced Joint Opening of Concrete Arch Dam
}

\author{
Gaochao $\mathrm{LI}^{\mathrm{a}, \mathrm{b}}$, Jie YANG ${ }^{\mathrm{a}, \mathrm{b}, 1}$, Anan $\mathrm{ZHANG}^{\mathrm{a}}{ }^{\mathrm{b}}$ and $\mathrm{Lin}_{\mathrm{CHENG}}{ }^{\mathrm{a}, \mathrm{b}}$ \\ anstitute of water Resources and Hydro-Engineering, Xi'an University of Technology \\ Xi'an, Shaanxi 710048, China \\ b State Key Laboratory of Eco-hydraulics in Nrothwest Arid Region of China, Xi'an \\ University of Technology, Xi'an, Shaanxi, 710048, China
}

\begin{abstract}
In order to study the relationship between joint opening changes of induced joints of concrete arch dam and dam leakage, combined with monitoring data analysis and finite element calculation method, the flow velocity distribution of six induced joints and seepage flow between joints under different openings were simulated. The correlation between joints and dam seepage and the influence of different openings on seepage flow between joints are clarified. The calculation results show that there is a strong correlation between dam leakage and joint opening, and it changes periodically with air temperature. Velocity distribution of induced joints is related to elevation. Compared with induced joints in the middle of riverbed, induced joints in the left and right bank abutments are closer. With the elevation increasing, the velocity between joints also increases gradually, and the seepage velocity near the drainage corridor is larger than that in other areas. With the increase of joint opening, the increasing rate of seepage decreases.
\end{abstract}

Keywords. Concrete arch dam, induction seam, seepage, finite element, measuring weir, leakage

\section{Introduction}

Concrete arch dam has the advantages of strong overload capacity, high safety, light and tough dam body and good elasticity. When the external load of the dam body increases or a part of the dam body cracks locally, the arch and beam action of the dam body will adjust itself, which will redistribute the stress of the dam body. However, during longterm operation or after suffering adverse load, with the local cracking and opening of arch dam joints increasing, the dam will have obvious leakage phenomenon, and longterm leakage will endanger the safety and stability of the dam. In the research of arch dam joints, from the point of view of influencing factors of arch dam transverse joint opening, Li Liang[1] explored the reasons of transverse joint opening during construction and the influence degree of influencing factors on joint opening, while Song Lingli[2] considered the influence of joint opening during dam pouring, arch sealing and water storage. The anti-cracking design and cracking effect of arch dam joints, cracking

${ }^{1}$ Corresponding Author, Jie YANG, Institute of water Resources and Hydro-Engineering, Xi'an University of Technology, Xi’an, China, E-mail: 962456707@qq.com. 
criterion of induced joints and failure mechanism of the joints were studied by Lihaifeng[3], Liu Haicheng[4] and Chen yuan[5]. Sun wei's[6] more attention was paid to the simulation of the joint unit. Scholars pay more attention to the causes of joints in arch dams and the influence of joint development on the structure, while concrete face rockfill dams have more research on joint opening and seepage. From the point of view of seepage analysis method, the situation of horizontal joint after the water stop failure is analyzed by Sheng jinbao[7]. The seepage calculation models of possible cracks in concrete face rockfill dam are studied by Li yanlong[8-9] and Wang ruijun[10-11] respectively, the former studied the seepage calculation models of cracks and gaps in concrete face; the latter studied the seepage model of concrete face slab joints and considered the seepage characteristics of face slab dams under extreme failure conditions. Then, the change law of leakage and seepage gradient caused by deterioration of the water stop at vertical joints of the face rockfill dam is explored by Zhangyu Jing[12]. Previous studies on variation laws of induced joint opening and seepage flow in concrete arch dams are few. In this paper, taking a concrete arch dam as an example, the finite element calculation method and monitoring data analysis are adopted. This paper analyzes the distribution law of joint velocity of concrete arch dam and the correlation between joint opening and seepage flow, thus providing basic reference for dam seepage safety.

\section{Two Seepage Three-Dimensional Finite Element Analysis Principle.}

\subsection{Seepage Finite Element Analysis Principle}

Seepage finite element calculation is to solve the water head function in seepage field and determine seepage parameters such as free surface and seepage flow in seepage field. The finite element method firstly transforms the seepage differential equation and boundary conditions into a functional extremum problem according to the variational principle, and then discretizes the continuum or research domain into a finite number of units. Finally, the algebraic equations are solved by computer.

\subsubsection{The Continuity Equation of Seepage Flow}

The continuity equation of seepage flow is established according to the principle of mass conservation. To study the equilibrium relationship of water flow, take an infinitely small parallelepiped in the seepage area filled with liquid. Let each side of the hexahedron be parallel to the three-dimensional coordinate axis and have a length of $\Delta x, \Delta y, \Delta z$, the seepage velocity component along the coordinate axis and the density of liquid are respectively used $v_{x}, v_{y}, v_{z}$ and $\rho$ to represent.

The quality change of liquid in parallelepiped is caused by the poor quality of liquid flowing into and out of parallelepiped. According to the law of conservation of mass, if they are equal in value, the continuity equation of seepage flow can be obtained as formula (1):

$$
\left[\frac{\partial\left(\rho v_{x}\right)}{\partial x}+\frac{\partial\left(\rho v_{y}\right)}{\partial y}+\frac{\partial\left(\rho v_{z}\right)}{\partial z}\right] \Delta x \Delta y \Delta z=\frac{\partial}{\partial t}[\rho n \Delta x \Delta y \Delta z]
$$


If the seepage is assumed to be an incompressible homogeneous liquid, and its density $\rho$ is a constant, the total mass difference between the liquid flowing into and flowing out of the parallelepiped is set to zero, the continuous equation of stable seepage is obtained as formula (2):

$$
\frac{\partial v_{x}}{\partial x}+\frac{\partial v_{y}}{\partial y}+\frac{\partial v_{z}}{\partial z}=0
$$

\subsubsection{Seepage Basic Differential Equation}

According to Darcy's law, seepage velocity in $\mathrm{x}, \mathrm{y}$ and $\mathrm{z}$ directions can be expressed. When the permeability in all directions is constant and water and soil are incompressible, it can be deduced as formula (3) and (4):

$$
\begin{gathered}
\frac{\partial}{\partial x}\left(k_{x} \frac{\partial H}{\partial x}\right)+\frac{\partial}{\partial y}\left(k_{y} \frac{\partial H}{\partial y}\right)+\frac{\partial}{\partial z}\left(k_{z} \frac{\partial H}{\partial z}\right)=0 \\
\frac{\partial^{2} H}{\partial x^{2}}+\frac{\partial^{2} H}{\partial y^{2}}+\frac{\partial^{2} H}{\partial z^{2}}=0
\end{gathered}
$$

Formula (4) is the basic differential equation of steady seepage. When the isotropic permeability is constant, the Laplace equation containing only one unknown number is obtained, and a definite solution is obtained in combination with the boundary conditions. When the water head at the boundary is known or the normal velocity at the boundary is known, the equation can be solved.

\section{Case Analysis}

\subsection{Project Overview}

A reservoir dam was a roller compacted concrete parabolic hyperbolic arch dam with normal water level of $880.00 \mathrm{~m}$, design flood level of $880.00 \mathrm{~m}$ and check flood level of $881.29 \mathrm{~m}$. The seepage monitoring system of the dam mainly used 8 water measuring weirs to measure in layers: in the first foundation corridor, four water measuring weirs are arranged according to the water flow situation, one measuring weir was on the left and right banks, and two measuring weirs were in front of the water collecting wells; One set was arranged on the left and right banks of the corridor on the second floor, and two sets were arranged in front of the water collecting wells, as shown in figure 1. During the construction period of water weir, water level measuring needle was used to measure water leakage, and automatic monitoring was used in the later period. Eighteen piezometers were set on the bank slopes of dam abutments on both banks to monitor the seepage around the bank slopes. Two holes were arranged in front of the grouting curtain on both banks, and seven holes were arranged along the streamline direction after the grouting curtain. Curtain grouting was divided into the first two layers of flat holes to design curtain lap holes, which connect the three parts of curtains into a whole to form a complete anti-seepage system. However, according to the present situation of on-site inspection of the reservoir and the leakage position of the downstream face of the dam body and the leakage situation inside the corridor, the leakage water is in the state of 
stream or even jet, and it was preliminarily judged that the leakage point was located near the induced joint of the dam body. Although grout for induced joints was replenished, leakage still existed, as shown in figure 2.

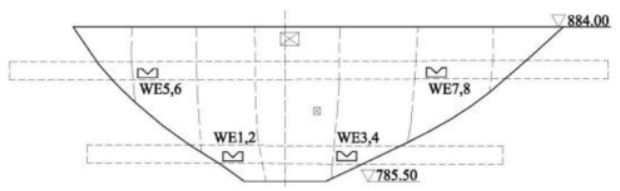

Figure 1. Spatial distribution of water measuring weir.
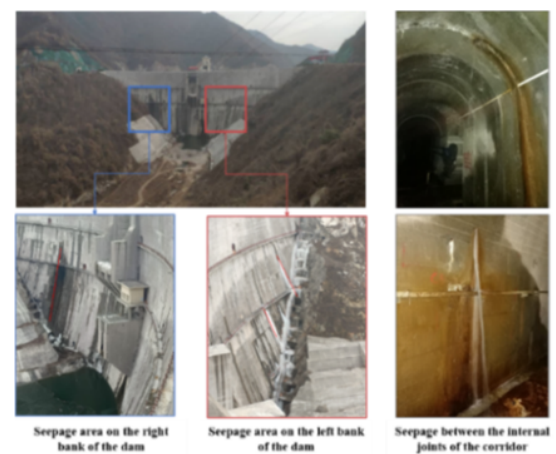

Figure 2. Current situation of reservoir dam leakage.

\subsection{Finite Element Model and Parameters}

The three-dimensional finite element model of seepage of the reservoir dam is shown in figure 3(a). The model consists of dam body, anti-seepage curtain, dam body induced joint, transverse joint and dam site area topography. The maximum distance between upstream boundary and dam body is $165.3 \mathrm{~m}$, and the maximum distance between the downstream boundary and dam body is $134.8 \mathrm{~m}$. The foundation is $118 \mathrm{~m}$ high. According to the actual construction inspection results, the anti-seepage effect of the anti-seepage system composed of anti-seepage curtains on both banks and vertical anti-seepage bodies on dam foundation is effective. Therefore, in the analysis, the unfavorable permeable geological models such as faults and fissures involved in grouting are not considered, and the calculation model is simplified. The finally determined finite element model for seepage calculation is shown in figure 4 below. The finite element mesh is mainly tetrahedral element, It consists of 284,856 units with 57,652 vertices, including 173,692 tetrahedral units in dam body, 8,591 pyramidal units and 39,429 grid nodes. The specific grid structure is shown in figure $3(\mathrm{~b})$.
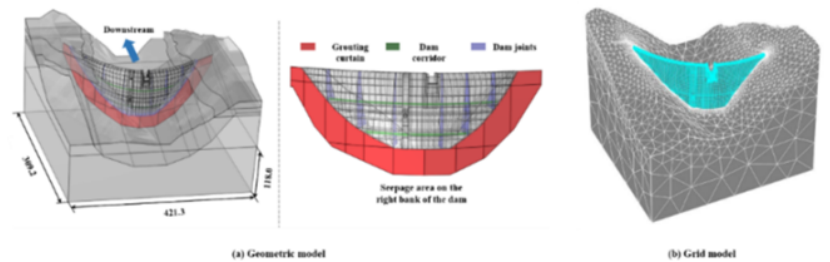

Figure 3. Calculation model of reservoir seepage. 
When calculating, all layers are treated according to the isotropy of permeability coefficient, and the initial calculated value of permeability coefficient takes the median value of the field measured range. Referring to the water pressure test results of dam foundation and abutment rock mass of reservoir project and considering the anti-seepage effect of water-stop structure between joints, the permeability coefficient adopted in each calculation domain of the model is shown in table 1 .

Table 1. Permeability coefficient of each computational domain.

\begin{tabular}{cc}
\hline material & Permeability coefficient $(\mathbf{c m} / \mathbf{s})$ \\
\hline Dam concrete & $1.5 \times 10^{-8}$ \\
Abutment rock mass & $7.5 \times 10^{-5}$ \\
Rock mass of dam foundation & $7.5 \times 10^{-5}$ \\
(above relative water-resisting layer) & \\
Rock mass of dam foundation & $1.5 \times 10^{-6}$ \\
(below relative water-resisting layer) & $3.0 \times 10^{-6}$ \\
Impervious curtain & $3.0 \times 10^{-5}$ \\
Seam room & \\
\hline
\end{tabular}

\subsection{Boundary Conditions and Calculation Conditions}

The water head boundary of upstream face and reservoir area is determined according to the characteristic water level of upstream face of dam body under various working conditions, while the water head boundary of downstream side and the river course is the corresponding natural river water level. When calculating the leakage condition of joints, the joints near the downstream leakage points found by on-site inspection are set as the internal fissure seepage boundary. The crack width is consistent with the actual joint opening. The velocity distribution and seepage flow of concrete dam joints under current working conditions are simulated, and the influence law of different joint openings on dam leakage is explored. The seepage calculation working conditions are proposed as follows:

- a. normal water level+joint seepage is not considered.

- b. normal water level+considering seepage between joints of actual dam body (real working condition).

- $\quad$ c. normal water level+considering actual seepage between joints of dam body (the joint openings of left $2 \#$ induced joint and right $2 \#$ induced joint are fully open).

\subsection{Calculation Results and Analysis}

\subsubsection{Analysis of Water Head Isoline}

\subsubsection{Joint Seepage Condition is Not Considered.}

Figure 4 illustrates that the water head isoline of the cross section of the central dam body along the river drops rapidly at the downstream drainage corridor, and the equipotential lines are densely distributed and the gradient is large, it corresponds to the large drainage channel flow in the corridor in the actual on-site inspection. Due to the anti-seepage effect of curtain grouting, the anti-seepage curtain area is in the rock stratum with certain water permeability. The difference of water head line between the upstream and downstream sides of the curtain is obvious, the downstream side is obviously reduced, and the water head isoline is gradually sparse, it shows that the anti-seepage curtain has 
a good anti-seepage effect. However, below the bottom line of the anti-seepage curtain is a relatively waterproof layer, which has little water permeability and its equipotential line changes uniformly.

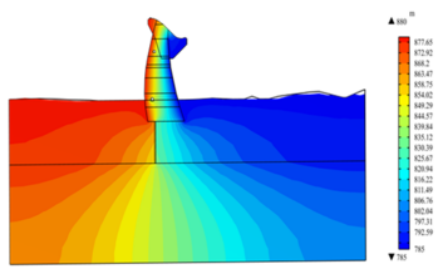

Figure. 4. Nephogram of the total water head along the river to the central section of the normal water level under a working condition of the reservoir.

Combined with the total head distribution of the model as a whole shown in figure 5, it shows that due to the better water retaining and seepage control effect of the dam, the upstream and downstream total heads have obvious changes, gradually decreasing from the upstream reservoir area to the downstream, the equipotential lines of the heads are concentrated in the dam body, and the saturated surface gradually drops to the downstream water level under the water retaining effect of the dam body. In addition, below the water level in the upstream reservoir area, the inside of the mountains on both sides of the river also shows the distribution state of wetting surface decreasing from upstream to downstream, it is consistent with the distribution trend of groundwater level in the upstream and downstream of the actual dam body, and the water level in the area where curtain grouting is located on both sides drops significantly. It reflects the good anti-seepage effect of curtain grouting at dam abutment.

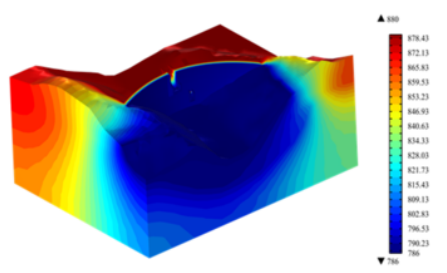

Figure. 5. nephogram of total water head of seepage field at normal water level under a working condition of reservoir.

\subsubsection{Considering the Seepage Condition of Joints.}

Firstly, the monitoring data of crack opening of induced joints near the leakage area are analyzed, and the left $2 \#$ induced joint with leakage is the main one, and the change of opening degree of measuring points between induced joints in 2020 is plotted, as shown in figure 6 . According to the overall trend, the opening degree of the measuring point above the first corridor on the upstream surface of the left $2 \#$ induced joint and the measuring point near the downstream surface is greatly affected by the change of external air temperature, and presents a periodic change rule with the change of external air temperature: the opening degree of the induced joint of the dam body is larger in the low temperature period in winter and smaller in the high temperature zone in summer, which told by the site manager that "compared with the high temperature period in summer, the leakage of dam body is bigger in winter. However, the measuring points below the first corridor have little annual change and are less affected by air temperature. At the same 
time, the change law of opening degree is consistent with the stress distribution law under the load of temperature rise and temperature drop: the maximum tensile and compressive stress of the dam body is basically located at the middle and upper elevation of the dam body. Therefore, there is a close relationship between the leakage of dam body and the change of opening degree of induced joint.
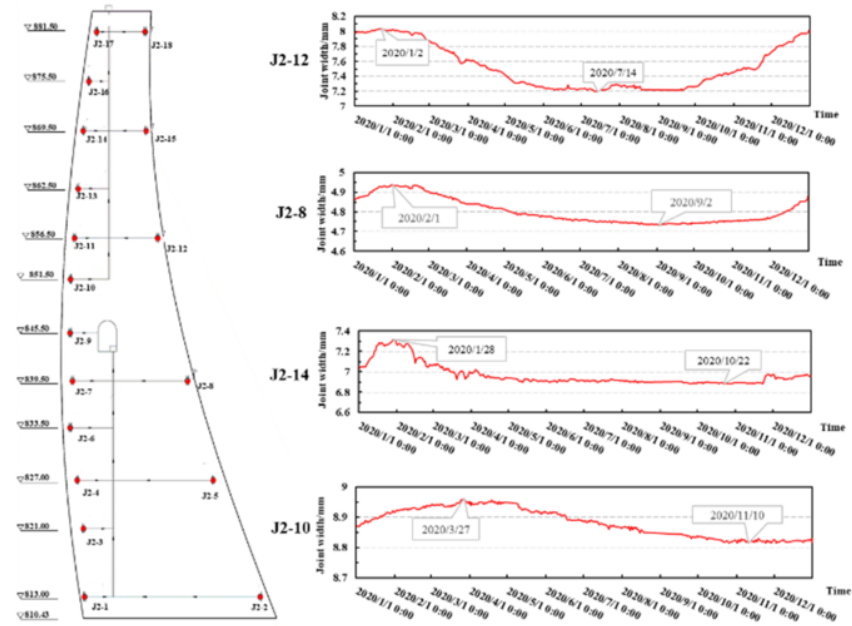

Figure 6. Change of opening degree of left 2\# induced joint of reservoir dam in 2020.

Figure 7 shows the cloud picture of water head distribution in the calculation area under the condition of normal water level+leakage of induced joints. It shows that the water head distribution law of mountain and dam foundation on both sides of the dam body has not changed much compared with the seamless working condition, and the obvious change is reflected in the two induced joints with serious leakage in the dam body, and the water head distribution in the leakage area is obviously different from that in the surrounding dam body without leakage. It can reflect the leakage working condition of induced joint set during simulation. As the leakage area is mainly at the joints of the dam body, it has little influence on the overall seepage field distribution of the model. Therefore, the distribution of water head in the maximum section of the dam body and the distribution of wetted surface in the calculation area are consistent with those under the condition of no leakage, and there is no obvious difference.

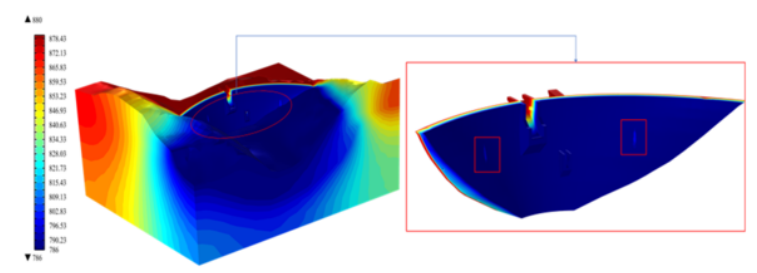

Figure 7. Nephogram of total water head of seepage field at normal water level under b working condition of reservoir. 


\subsubsection{Analysis of Seepage Flow}

The finite element simulation is carried out for three working conditions $\mathrm{a}, \mathrm{b}$ and $\mathrm{c}$, and the seepage flows of the left abutment mountain, the right abutment mountain, the bedrock at the lower part of the riverbed and the downstream riverbed without considering the joint seepage in working condition a are respectively $29.98 \mathrm{~m}^{3} / \mathrm{d}$, $26.05 \mathrm{~m}^{3} / \mathrm{d}, 10.91 \mathrm{~m}^{3} / \mathrm{d}$ and $41.81 \mathrm{~m}^{3} / \mathrm{d}$. As shown in table 2 for seepage flow of each part under working condition. The seepage quantity of the drainage corridor inside the dam body is $4.53 \mathrm{~m}^{3} / \mathrm{d}$, it shows that on the premise of good joint grouting of dam body, the upstream concrete impervious layer has better seepage control effect, and the seepage quantity of dam body is relatively small. It shows that from the streamline distribution diagram of the calculated area in figure 8 that the riverbed surface downstream of the normal water level is a waterless boundary. Under the action of high water head in the upstream reservoir area, the riverbed surface not only has permeated water from the upstream reservoir area and the lower rock mass, There is also infiltration of mountains on both sides of the river, and the seepage flow is relatively large. In addition, the velocity distribution below the grouting curtain line in the profile velocity vector is uniform, while the seepage control curtain and dam foundation have obvious velocity changes, and the seepage path increases, it reflects the effectiveness of the seepage control curtain.

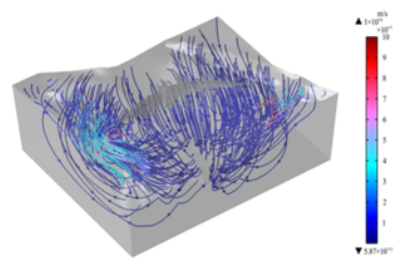

Figure 8. Streamline distribution of normal water level under a working condition of reservoir

For working conditions $\mathrm{b}$ and c considering dam leakage, in addition to the statistics of seepage flow of each part in the conventional calculation domain, statistics are also made on the seepage flow of six induced joints of the dam. As shown in table 2 for seepage flow of each part of working condition $b$ and seepage flow of different induced joints of the dam. Compared with the seepage quantity of each part of working condition a without considering seepage under the same water level, except the dam corridor, there is little difference in seepage flow at each part, it shows that dam leakage has little influence on dam foundation and seepage around the dam on both sides. In addition, with the increase of joint opening, the leakage of the left $2 \#$ induced joint and the right $2 \#$ induced joint increased, but it did not increase linearly with the increase of joint opening, but the increasing rate of leakage gradually decreased. The seepage quantity of other induced joints is reduced appropriately. It can be seen that the increase of joint opening directly affects the increase of seepage quantity, and there is a non-linear growth relationship, and the leakage quantity of surrounding joints decreases numerically. 
Table 2. Calh part under each working condition

\begin{tabular}{ccc}
\hline Calculated position & $\begin{array}{c}\text { a working condition flow } \\
\left(\mathbf{m}^{\mathbf{3}} / \mathbf{d}\right) \mathbf{r}\end{array}$ & $\begin{array}{c}\text { b working condition flow rate } \\
\left(\mathbf{m}^{\mathbf{3}} / \mathbf{d}\right)\end{array}$ \\
\hline Downstream riverbed & 41.81 & 42.72 \\
Drainage gallery & 4.53 & 4.87 \\
Left abutment mountain. & 29.98 & 29.98 \\
Right abutment mountain. & 26.05 & 29.03 \\
Bedrock under riverbed. & 10.91 & 10.91 \\
\hline & b working condition single & c working condition single \\
Induction seam number & width flow & width flow \\
& $\mathbf{m}^{\mathbf{3}} /(\mathbf{d} \cdot \mathbf{d} \cdot \mathbf{m})$ & $\mathbf{m})$ \\
\hline Left 1\# & 0.045 & 0.038 \\
Left 2\# & 8.70 & 10.166 \\
Left 3\# & 0.050 & 0.050 \\
Right 1\# & 0.048 & 0.045 \\
Right $2 \#$ & 7.78 & 13.056 \\
Right 3\# & 0.053 & 0.045 \\
\hline
\end{tabular}

As shown in the figure 9, compared with other induced joints, the leakage of right2\# and left 2\# induced joints is obviously increased, and the flow velocity is much larger than other induced joints, and the maximum flow velocity is not of the same order of magnitude. In addition, the seepage flow velocity distribution near the induced joints of the left and right bank abutments is relatively uniform, and the flow velocity and seepage volume are relatively small, it is mainly due to the small head upstream of the induced joints near the abutments on both banks and the low height of the induced joints. For the induced joints in the middle of the riverbed, the velocity distribution is related to the elevation. With the elevation increasing, the velocity between joints increases gradually, and the seepage velocity near the drainage corridor is larger than that in other areas.

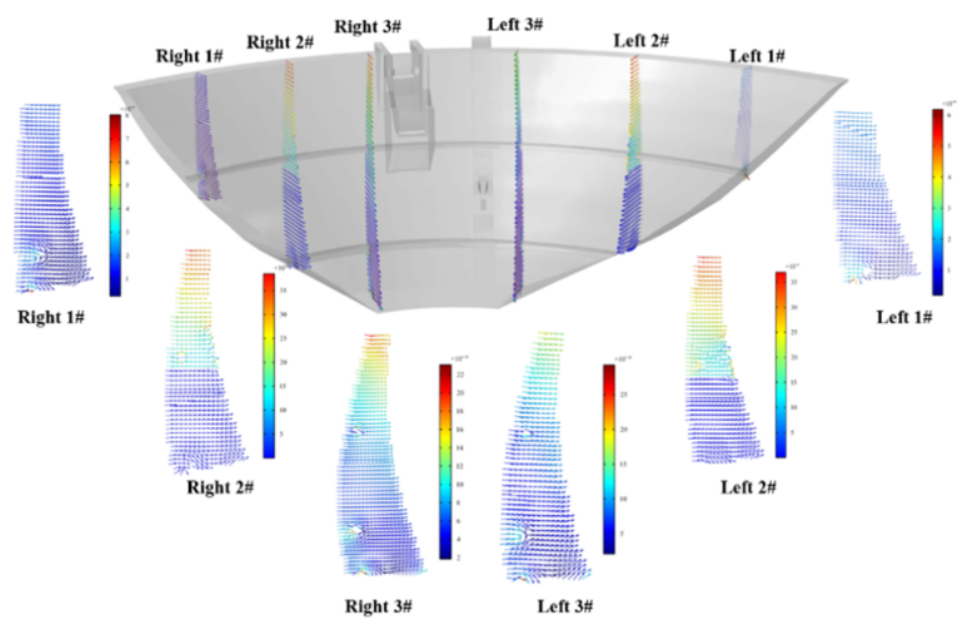

Figure. 9. Streamline distribution of induced joints in reservoir under b working condition. 


\section{Conclusion}

Through simulating three working conditions of the dam and comparing and analyzing comprehensively, the following conclusions are obtained:

- In the three working conditions, curtain grouting plays a very good role in protecting the dam leakage around both banks, and the curtain grouting effect plays a vital role in the stability of the dam body.

- Combined with the analysis of monitoring data and on-site inspection, it can be seen that the joint is obviously affected by temperature, showing seasonal changes: the opening degree is larger in the low temperature period in winter and smaller in the high temperature zone in summer. The leakage of induced seams is mainly left $2 \#$ induced seam and right $2 \#$ induced seam,

- From the numerical simulation results, it can be seen that the increase of joint opening directly affects the increase of seepage flow, and with the increase of joint opening, the increase rate of seepage flow gradually decreases, and the induced joint leakage has little influence on the seepage of mountain and dam foundation on both banks.

\section{References}

[1] LI Liang, ZHOU Wei, CHANG Xiaolin, HUA Youhe, WANG Yi. Analysis of transverses joints aperture of high arch dam and its influencing factors[J]. Water Resources and Power. 2015;33(07):84-88.

[2] SONG Lingli, LI Manlin, CHANG Xiaolin, PAN Yanfang. Simulation analysis of transverse joints aperture for Dagangshan arch dam[J]. Engineering Journal of Wuhan University. 2013;46(S1):446-450.

[3] LI Haifeng, YANG Bo, ZHANG Guoxin, XU Xiuming. Comparative study on effect induced joints of different interface patterns[J]. Journal of hydraulic engineering. 2017;48(10):1167-1174+1184.

[4] LIU Haicheng, WU Zhimin, SONG Yupu. Study on damage and fracture criterion for induced joints of RCC arch dams. Journal of hydroelectric engineering. 2004(05):22-27.

[5] CHEN Yuan, ZHANG Lin, ZHOU Kun, HU Chengqiu. Study on joint types and destructive mechanism of high RCC arh dams[J]. Journal of hydraulic engineering. 2005(05):519-524.

[6] SUN Wei, HE Yunlong, XIONG Kun, MIAO Jun. Thin-layer joint element and its application on simulation of arch dam structure joints[J]. Journal of sichuan university(engineering science edition). 2014,46(S2):26-35.

[7] SHENG Jinbao, LI Lei. Preliminary study on seepage analysis methods of concretr-face dams[J]. Journal of nanjing hydraulic research institute. 2000(02):39-43.

[8] LI Yanlong, WANG Ruijun, LI Shouyi ,DING Lujun. Seepage calculation model for face slab joint and crack of concrete face rockfill dam[J]. Chinese journal of applied mechanics. 2010.27(01):145-150+230.

[9] LI Yanlong, LV Haidong. Study on seepage calculation model for the concrete face slab with cracks[J]. Journal of basic science and engjneering. 2009.17(05):668-674.

[10] WANG Ruijun, LV Haidong, LU Li. Study on seepage calcution model of slab joints of CFRD[J]. Jour. of northwest Sci-Tech Univ. of Agri. and For.(Nat.Sci.Ed.). 2006.(09):171-175.

[11] WANG Ruijun, LV Haidong, LI Yanlong. Study on seepage characteristics of CFRD under extreme condition of slabs being destroyed[J]. 2007(03):37-41.

[12] ZHANG Yunjing, ZHENG Dongjian, RUAN Hongsong, WU jinrong. Measuring weir monitoring analysis of water sealing deterioration process in vertical joints of a concrete faced rockfill dam[J]. 2019,39(05):73-77. 